\title{
MIGRAÇÃO DE FUNDOPLICATURA E DO ESTÔMAGO PARA O HEMITÓRAX DIREITO COMO COMPLICAÇÃO IMEDIATA DE CARDIOPLASTIA VIDEOLAPAROSCÓPICA EM DOENTE PORTADOR DE AMILOIDOSE
}

\section{MIGRATION OF FUNDOPLICATURE AND STOMACH TO RIGHT THORAX AS IMMEDIATE COMPLICATION OF LAPAROSCOPIC ANTIREFLUX SURGERY IN A PATIENT WITH AMYLOIDOSIS}

\author{
Nelson de Souza Liboni, ACBC-SP ${ }^{1}$ \\ Rodrigo Altenfelder Silva, TCBC-SP ${ }^{2}$
}

\section{INTRODUÇÃO}

A amiloidose produz deposição extracelular de um material proteináceo, que com a progressão da doença pode comprimir e destruir os tecidos adjacentes.

Os autores relatam um caso de migração da válvula anti-refluxo para o hemitórax direito após cardioplastia videolaparoscópica, em doente portador de doença do refluxo gastroesofágico ( DRGE) e amiloidose, discutindo aspectos diagnósticos e terapêuticos.

\section{RELATO DE CASO}

Trata-se de doente do sexo masculino, ascendência asiática, 56 anos, com diagnóstico de amiloidose associada à DRGE, hérnia hiatal (com $3 \mathrm{~cm}$ de deslizamento intratorácico) e esofagite erosiva , cuja manometria mostrou hipotonia do esfíncter inferior do esôfago e a Ph-metria refluxo patológico.

Foi submetido a cardioplastia videolaparoscópica com válvula mista tipo Brandalise. Na crurorrafia, os pilares diafragmáticos foram expostos e se apresentavam com aspecto mais adelgaçado e nacarado. Realizou-se a hiatoplastia com ponto em " $X$ ", utilizando-se fio de poliéster 2-0. Não foi seccionado o ligamento gastrolienal para liberação do fundo gástrico na realização da válvula , pois não havia tensão.
Após 30 horas de pós-operatório, já recebendo alimentação, apresentou quadro de tosse intensa, seguindose náuseas, vômitos e dispnéia.

Submetido à radiografia simples de tórax, encontrouse imagem sugestiva de pneumotórax no hemitórax direito, com apagamento dos contornos do diafragma e do coração (Figura 1).

Solicitado exame contrastado de esôfago e estômago para avaliar a existência de câmara gástrica no tórax, notando-se nível hidroaéreo no hemitórax direito, suge-

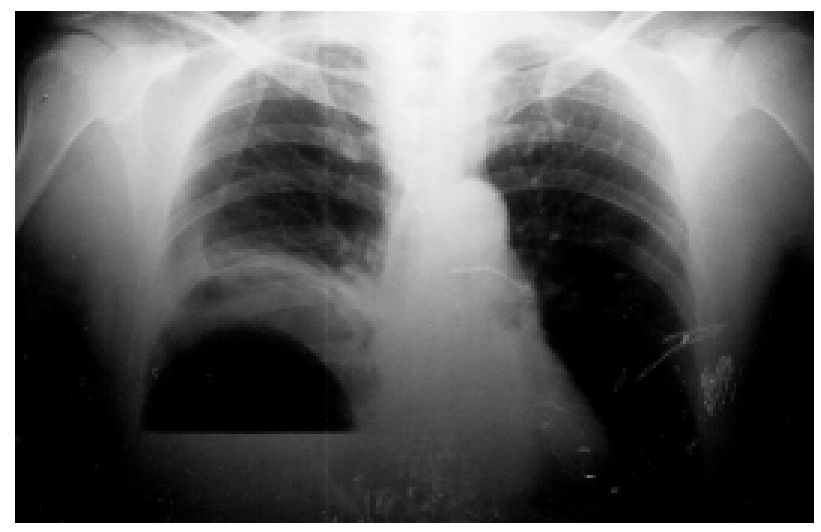

Figura 1 - Raio X de tórax.

1. Médico Assistente da Santa Casa de São Paulo

2. Professor Assistente da Faculdade de Ciências Médicas da Santa Casa de São Paulo

Recebido em 21/11/2000

Aceito para publicação em 06/06/2001

Trabalho realizado no Hospital Alemão Oswaldo Cruz-SP. 
rindo a presença do estômago. Na suspeita da migração do estômago para o tórax foi feita uma tomografia computadorizada de tórax que mostrou pneumotórax na porção médio basal, atelectasia restritiva e aspecto de volvo gástrico herniado à direita, sem extravasamento de contraste (Figura 2).

Indicada a reoperação, optou-se pela laparotomia mediana como via de acesso, encontrado o estômago migrado completamente para o hemitórax direito. $\mathrm{O}$ fio da crurorrafia estava rompido, embora o nó estivesse intacto. A válvula anti-refluxo estava desfeita, sem sinais de necrose ou perfuração gastroesofágica. Realizada a redução do conteúdo gástrico para o abdome, refazendo-se a hiatoplastia com fio de seda 0 através de dois pontos em " $X$ ". Refeita a válvula anti-refluxo à Nissen, com fio de algodão 2-0. Associou-se drenagem pleural à direita.

O paciente evoluiu bem, recebendo alimentação em 48 horas de pós-operatório. Permaneceu internado por sete dias para tratamento de pneumonia em pulmão direito, recebendo alta hospitalar sem outras complicações.

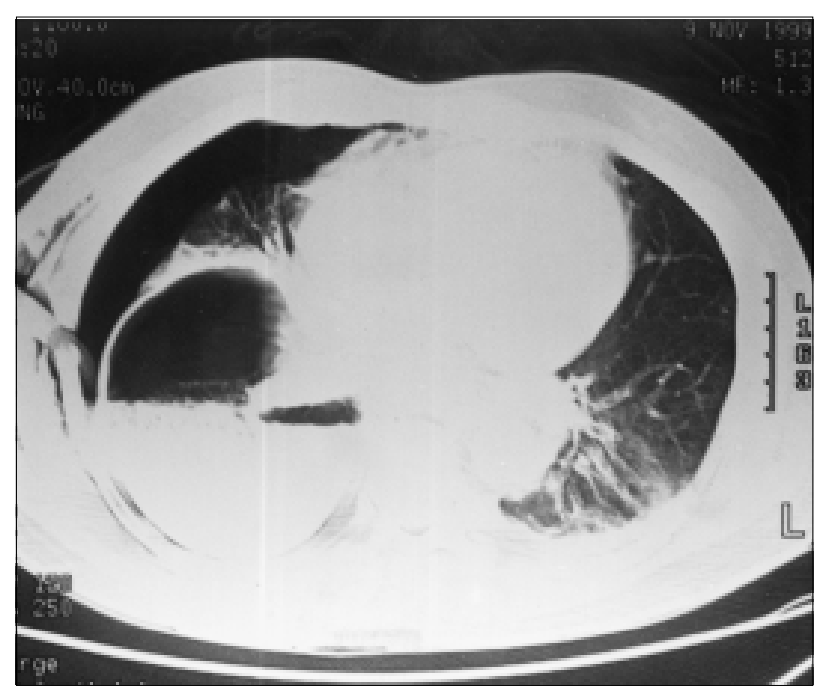

Figura 2 - Tomografia de tórax.

\section{DISCUSSÃO}

A cardioplastia por videolaparoscopia tem se mostrada segura e efetiva no tratamento da DRGE, com taxas de morbidade de $5 \%$ a $20 \%$ e mortalidade inferior a $1 \% 1$. Dentre as principais complicações descritas destacam-se: a disfagia, hemorragia, pneumotórax, as perfurações do esôfago ou do estômago, a síndrome da distensão gasosa, o rompimento da válvula e a migração ou deslizamento da válvula para o tórax.

O rompimento da válvula é uma complicação rara e decorre da deiscência da sutura geralmente após tosse, vômito ou distensão do estômago.

A migração da válvula para o tórax está presente em $2 \%$ a $6 \%$ dos casos, podendo ocorrer precoce ou tardia- mente ${ }^{1-5}$. É mais rara para o hemitórax direito e está relacionada com a aproximação inadequada dos braços do pilar direito diafragmático, mobilização insuficiente do fundo gástrico, falha técnica na realização da sutura ou utilização de fios inadequados.

Alguns aspectos técnicos, para evitar essas complicações são descritos, embora ainda existam controvérsias ${ }^{1,3}$.

A liberação do fundo gástrico e a secção dos vasos curtos, preconizadas por muitos autores, permitem maior mobilidade do estômago e facilitam a confecção da válvula. No entanto, existem casos em que esta manobra não é necessária e a temos utilizado seletivamente ${ }^{2}$.

A crura deve ser individualizada e aproximada com pontos separados ou em " $X$ ", utilizando-se fios inabsorvíveis. Para evitar disfagia no pós-operatório, pode-se passar uma sonda grossa no esôfago ou tomar o cuidado de deixar uma distância de cerca de $1 \mathrm{~cm}$ entre a sutura da crura e o esôfago.

A valvuloplastia não necessita ter mais que 2 a $3 \mathrm{~cm}$ de extensão para evitar o refluxo, o que é conseguido com a utilização de três a quatro pontos de fio inabsorvível.

A sonda nasogástrica pode ser deixada no pós-operatório imediato, com a finalidade de evitar a distensão, embora muitos doentes não se queixem, quando a mesma é retirada após a cirurgia ${ }^{2}$.

Os sintomas da migração da válvula se tornam mais nítidos quando acompanhados pelo encarceramento gástrico ou volvo do estômago. Em geral são precedidos de tosse, náusea e vômitos, seguido de quadro de desconforto abdominal, dor torácica ou abdominal e dispnéia.

Providências imediatas devem ser tomadas para o diagnóstico. Os exames de imagem que mais ajudam são: a radiografia simples de tórax, a radiografia contrastada de esôfago e a tomografia computadorizada de tórax.

Feito o diagnóstico, deve ser programada a cirurgia o mais breve possível para evitar a necrose e ou perfuração gástrica.A morbidade nestes casos pode ser de $70 \%$ e a mortalidade de $4,9 \%$.

Neste caso, optamos pela laparotomia exploradora como via de acesso, mas a re-intervenção pode ser feita por videolaparoscopia. A reoperação precoce favorece a identificação dos pilares e a realização da nova válvula. Quando existe retardo na indicação, pode-se encontrar isquemia do estômago ou perfuração com contaminação da cavidade peritoneal e do mediastino, piorando o prognóstico.

Ficamos na dúvida em relação à causa do rompimento da crurorrafia. Embora o nó estivesse intacto, o fio havia se rompido. Não sabemos se a válvula ficou com tensão suficiente para se romper durante o quadro de tosse no pós-operatório, ou se houve alguma interferência da amiloidose, uma vez que o tecido muscular dos braços do pilar se encontravam alterados.

Em todo caso, optamos pela aproximação dos braços do pilar através de dois pontos em " $X$ " com fio de seda 0 , além de refazermos a válvula com pontos de fio de algodão. A boa evolução no pós-operatório sugere que, nesses casos, o reforço da crurorrafia e da válvula anti-refluxo pode diminuir os índices de complicações. 


\section{ABSTRACT}

Patients with amyloidosis show deposits of protein cells that, with progression of the disease, can compress and destroy adjacent tissues and organs. The authors present a case of migration of fundoplicature after laparoscopic in surgical patients with gastroesophageal reflux symptoms (GER) and amyloidosis, into the right thorax, discussing the aspects of diagnosis and treatment.

Key Words: Fundoplication; Amyloidosis; Laparoscopic; Video assisted surgery, Pos operative complication.

\section{REFERÊNCIAS}

1. Kozarek RA, Low DE, Raltz SL et al. Complications associated with laparoscopic anti-reflux surgery:one multispecialty clinic's experience.Gastrointest Endosc; 1997, 46(6):527-31

2. Hinder RA, Filipi CJ, Wetscher G et al. Laparoscopic Nissen Fundoplication is an effective treatment for gastroesophageal reflux disease. Annals Surgery; 1994, vol. 220. No. 4.472-483

3. Edye MB, Canin-Endres J, Gattorno F et al. Durability of laparoscopic repair of paraesophageal hernia. Ann Surg; 1998, 228(4):528-35

4. Stein HJ, Feussner H, Siewert JR. Failure of antireflux surgery:causes and management strategies. Am J Surg; 1996, 171(1):36-9
5. Marchesini JB, Malafaia O. Doença do Refluxo Gastroesofágico. Colégio Brasileiro de Cirurgiões, Editora Atheneu, 1996.

Endereço para correspondência:

Dr. Nelson de Souza Liboni

R. Maestro Cardim, 1236, Paraíso

01323-001 — São Paulo-SP 